\title{
Spreading of Excellence in SARNET Network on Severe Accidents: The Education and Training Programme
}

\author{
Sandro Paci ${ }^{1}$ and Jean-Pierre Van Dorsselaere ${ }^{2}$ \\ ${ }^{1}$ Dipartimento di Ingegneria Civile e Industriale (DICI), Università di Pisa, Via Diotisalvi 2, 56126 Pisa, Italy \\ ${ }^{2}$ Nuclear Safety Division, Institut de Radioprotection et de Sûreté Nucléaire (IRSN), Cadarache, BP3, \\ 13115 Saint-Paul-Lez-Durance Cedex, France
}

Correspondence should be addressed to Sandro Paci, sandro.paci@ing.unipi.it

Received 18 August 2012; Revised 19 October 2012; Accepted 21 October 2012

Academic Editor: Leon Cizelj

Copyright (C) 2012 S. Paci and J.-P. Van Dorsselaere. This is an open access article distributed under the Creative Commons Attribution License, which permits unrestricted use, distribution, and reproduction in any medium, provided the original work is properly cited.

The SARNET2 (severe accidents Research NETwork of Excellence) project started in April 2009 for 4 years in the 7th Framework Programme (FP7) of the European Commission (EC), following a similar first project in FP6. Forty-seven organisations from 24 countries network their capacities of research in the severe accident (SA) field inside SARNET to resolve the most important remaining uncertainties and safety issues on SA in water-cooled nuclear power plants (NPPs). The network includes a large majority of the European actors involved in SA research plus a few non-European relevant ones. The "Education and Training" programme in SARNET is a series of actions foreseen in this network for the "spreading of excellence." It is focused on raising the competence level of Master and Ph.D. students and young researchers engaged in SA research and on organizing information/training courses for NPP staff or regulatory authorities (but also for researchers) interested in SA management procedures.

\section{Introduction}

Despite the accident prevention measures adopted in modern NPPs, some accident scenarios, in very low probability circumstances, may result in a SA, as shown in the accident that occurred at the Fukushima Daiichi NPP in March 2011, with nuclear fuel melting and dispersal of radioactive materials into the external environment, thus constituting a hazard for the public health and for the environment. Significant progress has been achieved since the 1980s in the understanding of a SA progress, thanks in particular to the several research actions carried out inside the different EC FPs, but several "open issues" still need further research activities to reduce uncertainties and consolidate SA management plans $[1,2]$.

Facing the increasing reduction of the national budgets on SA researches, in 2003 EC judged necessary a better coordination of the single national efforts in this field to preserve and optimise the use of the available expertise and of the experimental facilities, in order to resolve the remaining "open issues" for enhancing the safety of existing and future
NPPs. In April 2004, 51 worldwide organisations involved in $R \& D$ on SA, including research organisations, safety authorities, technical safety organisations (TSO), industries, utilities, and universities, decided to network together in SARNET, in the framework of the EC FP6, linking their capacities of research in the SA area in a consolidated manner [3] in a network of excellence, that is, an instrument for strengthening excellence by tackling the fragmentation of the European research, where the main deliverable is a durable structuring and shaping of the way that research is carried out on the topic of the network. A second phase of this excellence network (SARNET2) has started in April 2009, again supported by EC during the present FP7, for a duration of 4 years and again under the coordination of the French "Institut de Radioprotection et de Sûreté Nucléaire" (IRSN). The SARNET2 partners contribute to a joint programme of activities (JPA) including, in the framework of education and training, the following main actions:

(i) development of education courses on SA for students and researchers, and training courses for specialists, 
(ii) promotion of personnel mobility amongst various European organisations,

(iii) organisation of large international conferences on SA researches.

This education and training programme has been set up to disseminate the excellence and knowledge in the SA area, including out of the SARNET2 network perimeter. It is intended to be an in-depth treatment so that the university students and researchers will be able to (a) understand and (b) develop the methodology in the topics further and (c) use analysis tools more effectively. In particular, the mobility programme under which students (including students from European universities out of the SARNET2 perimeter) and researchers will be able to go into different laboratories of SARNET2 partners for training will complete this education and training programme to develop a common safety culture throughout Europe. Links with the ENEN (European Nuclear Education Network) association have been also strengthened, ENEN being a nonprofit international organisation established on September 2003 under the French Law of 1901 with the mission of the preservation and further development of expertise in the nuclear fields by higher education and training.

\section{The SARNET Excellence Network}

Forty-seven partners from Europe, Canada, India, South Korea, United States, and Japan participate currently in SARNET with an overall manpower that represents about 40 persons per year (230 researchers and more than 20 $\mathrm{Ph} . \mathrm{D}$. students are involved in the network). This excellence network has been defined in order to optimize the use of the available research budget and to constitute a sustainable consortium in which common research programmes in the SA area and a common SA code (ASTEC) are developed. The ASTEC integral code [4] plays a key role in the network, by capitalizing SA knowledge through the implementation inside the code of the new physical models that are produced by the network itself.

In the SARNET network structure (Figure 1), a steering committee is in charge of strategy and decisions, advised by an advisory committee, composed of external enduser organisations (utilities or safety authorities). A general assembly, composed of one representative of each SARNET partner, plus the EC representative, is called periodically for information and consultation on the progress of the activities, the work orientations and the steering committee decisions. A management team, composed of the network coordinator and of the work package (WP) leaders, is entrusted with the day-to-day management of the network. The performed JPA is broken down into 8 WPs, pertaining to the three following types of activities:

(a) integrating activities, aiming at the management of the network and at strengthening links among the partner organisations (WP1 on management, WP3 on information systems and WP4 on ASTEC code),

(b) joint research activities (from WP5 to WP8), (c) spreading of excellence in WP2 (analysed in detail in the following).

About 320 papers related to SARNET activities in the last 7 years have been presented in conferences or published in scientific journals. The dissemination of internal and public information is also done through periodic open newsletters, two websites (the public one and the restricted one) and the participation of the members to public events. After the midterm of the project, the paper in [5] presents a more detailed SARNET2 description and a few recent outcomes of joint research done by the network members.

\subsection{Integrating Activities}

2.1.1. ASTEC Code Assessment and Improvements (WP4). IRSN and German Gesellschaft für Anlagen und Reaktorsicherheit $\mathrm{mbH}$ (GRS) jointly develop the ASTEC code to describe the complete evolution of a SA in a water-cooled reactor, including the behaviour of engineered safety systems and procedures used in SA management (SAM). The series of code versions V2 aims at covering all European NPPs and the new Gen. III light water reactor (LWR) designs; it can simulate the EPR (European pressurised reactor), especially its external core-catcher, and it includes the advanced core degradation models of the IRSN ICARE2 mechanistic code.

Both organisations also assure the code maintenance and the support to the code users, notably through annual ASTEC Users' Club meetings. In fact, twenty-eight organisations actively collaborate on the development and in the assessment of the successive ASTEC versions. The code assessment activity mainly consists in covering a broad matrix of reactor applications, aiming at the most important SA scenarios for 4 types of water reactors (PWR, BWR, VVER, and CANDU) present in Europe. In complement to these reactor applications, ASTEC assessment continues through calculations of a wide range of experiments in different SA areas, such as the Phébus FP experiments [6] and of real plant accidents such as TMI2 and Fukushima-Daiichi sequences.

2.1.2. Information Systems (WP3). A public website (http:// www.sar-net.eu/) is open since 2009 in order to provide information on SARNET2 activities or events and, more generally, on the SA research field to the general public. For the internal communication and file sharing among all the network members, the e-collaborative internet advanced communication tool (ACT) is used.

One of the main SARNET goals is also to collect and preserve, for future utilizations, the large quantity of today's available SA experimental data, in order to ensure their preservation, exchange, and processing, including all the related documentation. The data collected inside DATANET are both previous experimental data that partners are voluntary willing to share and all new experimental data produced within SARNET since 2004. DATANET is actually 


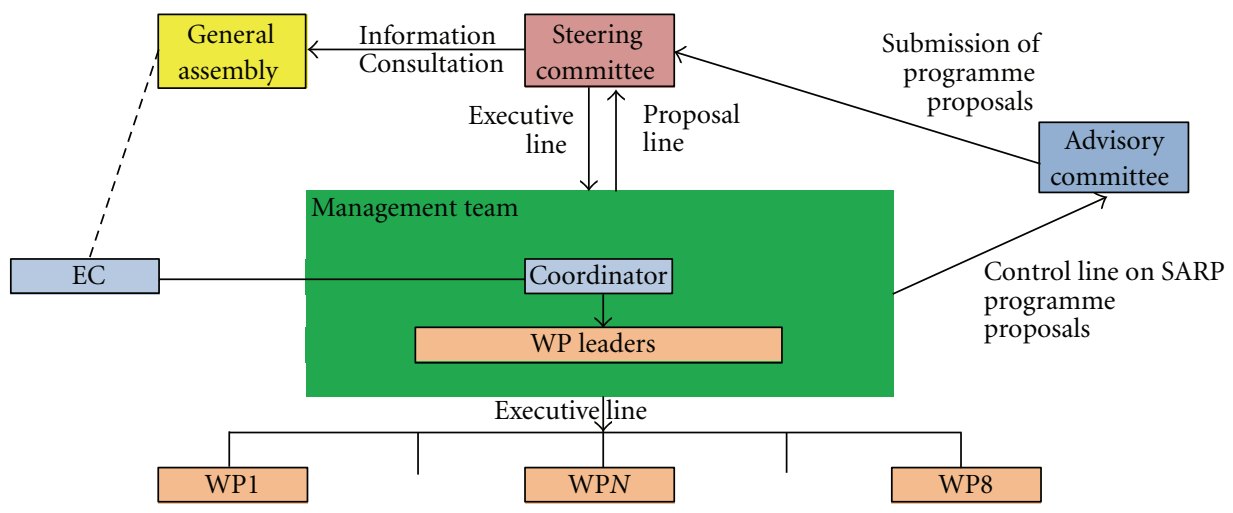

FIGURE 1: Structure of the SARNET network.

based on the STRESA tool [7], managed by the JRC Institute for Energy in Petten (Netherlands).

2.2. Joint Research Activities. One of the achievements of SARNET consisted in obtaining a European consensus on six high priority issues on which research was still considered as necessary. These six open safety issues, selected at the beginning of the SARNET2 project, are analysed inside the WPs 5 to 8 :

(1) core coolability during reflooding and debris cooling-WP5,

(2) ex-vessel melt pool configuration during molten corium concrete interaction (MCCI), ex-vessel corium coolability by top flooding-WP6,

(3) melt relocation into water, ex-vessel fuel coolant interaction (FCI) - WP7,

(4) hydrogen mixing and combustion in containmentWP7,

(5) oxidising impact on source term-WP8,

(6) iodine chemistry in reactor coolant system (RCS) and in containment-WP8.

The experimental efforts carried out in SARNET2 are mainly devoted to two of these open issues, for which a real progress toward the "closure" of the issue itself is expected: "corium/debris coolability" and MCCI. For all these six issues, the same method is adopted: review and selection of available relevant experiments, contribution to the definition of new test matrices, synthesis of the interpretation of experimental data, benchmark exercises among available codes, review of models, and synthesis and proposals of new or improved models to be implemented inside ASTEC.

The ranking of $\mathrm{R} \& \mathrm{D}$ priorities has been recently reviewed and updated to take into account the Fukushima-Daiichi accident that took place in Japan in March 2011. No strong evolution of priorities was concluded, but a few new subjects were identified where the efforts must be increased in the next years.

Indeed a key integration aspect of the SARNET network is the setup of the "technical circles," each covering a specific detailed topic. These technical circles, experimented with success in the recent past for the PHEBUS FP experimental programme $[8,9]$, bring experimenters and modellers closer together, concerning test definition, interpretation and model development.

2.2.1. Corium and Debris Coolability (WP5). The major motivation is to solve the remaining uncertainties on the possibility of cooling structures and materials during a SA sequence, either in the core or the vessel bottom head or in the reactor cavity, in order to limit the accident progression. This could be achieved by water injection either by ensuring corium retention within the vessel or at least slowing down the corium progression and limiting the flow rates of corium release into the reactor cavity. These issues are covered within SAM for current reactors and also within the scope of the design and safety evaluation of future reactors. The following 3 key situations and processes are analysed inside this WP5:

(a) reflooding and coolability of a degraded core,

(b) remelting of debris, melt pool formation, and coolability,

(c) ex-vessel debris formation and coolability.

2.2.2. Molten Corium Concrete Interaction (WP6). The addressed main situation is the reactor pit initially dry but with the possibility of water injection later during MCCI. The work programme is complementary with the OECD/NEA (Nuclear Energy Agency) MCCI project that finished in 2011 [10]. Recent experiments [11] have provided new results that questioned the reliability of the available models and their extrapolation to reactor conditions. As an example, it becomes clear that new effects have to be taken into account to be able to describe the ablation anisotropy observed in case of silica-rich concrete and the different behaviour of limestone common sand concrete. This ablation anisotropy was also present in the ablation of the Chernobyl silica-rich concrete. The intention is thus to gain sufficient experimental data in order to determine which phenomena are responsible for the observed isotropy/anisotropy of the concrete ablation. 
2.2.3. Containment Issues (WP7). The considered issue is the threat to the containment integrity due to two types of highly energetic phenomena: steam explosion and hydrogen combustion. Steam explosion may be caused by ex-vessel FCI due to a vessel failure and pouring of the corium in the flooded reactor cavity. Hydrogen combustion may be caused by ignition of a gas mixture with high local hydrogen concentrations, which may be due to the imperfect mixing of the containment atmosphere. Phenomena, as the containment atmosphere stratification, influencing these threats are considered as well.

Several benchmarks were launched inside this WP7, involving simulation codes on different physical phenomena or safety systems influencing the behaviour of the containment atmosphere, such as containment sprays [12], hydrogen combustion, steam condensation [13], interaction between passive autocatalytic recombiners and containment atmosphere, and a theoretical benchmark on the thermohydraulics behaviour of a generic NPP containment [14] for in-deep comparison of several codes and code users.

2.2.4. Source Term (WP8). The overall objective is to reduce the uncertainties associated with calculating the potential releases of radiotoxic fission products to the external environment. WP8 activities are concentrated on iodine and ruthenium, given their high radio-toxicity, noting that the ruthenium release is enhanced in oxidising atmospheres, such as those that may follow air ingress into the RCS. The research treats the transport of these elements through the RCS and their behaviour in the containment. Of particular importance is the prediction of volatile iodine and ruthenium species in the containment, forms that are hard to remove by containment sprays or by filtration while the venting of the containment system is actuated.

Full advantage is taken of cooperation with international programmes such as Phébus FP, International Source Term Programme (ISTP) [6], and programmes of OECD/NEA/CSNI, to avoid duplication of experiments, to help the consistency of the programmes and to identify the remaining needs in this field.

\section{The SARNET Education and Training Programme}

The "Education and Training" Programme, included in the WP2 "spreading of excellence," is focusing on the following.

(a) Raising the competence level of the European university students (Master and Ph.D.) and young researchers engaged in SA research. Towards this purpose, in the streamline of what was done in the SARNET FP6 project, new educational courses have been developed on the SA phenomenology. Four oneweek educational courses, the last one held in Pisa (Italy) in January 2011, were organised since 2005, gathering from 40 to 100 young participants.

(b) Organisation of information/training short courses for staff of NPPs or regulatory authorities (but also for interested researchers) mainly involved in SA management (SAM) procedures. In this kind of course, the emphasis is not only on SA phenomenology, as in educational ones, but also on identifying what these SAM procedures are based on and why they are effective for the plant protection. The last 2-day information/training course was organized in Karlsruhe (Germany) by the Karlsruhe Institute of Technology (KIT) in July 2012, gathering 32 participants from 11 different countries, including 3 non EU countries (Canada, Mexico, and Russia).

(c) Publication at the beginning of 2012 of the SARNET text book on SA phenomenology [15] of 700 pages long written internally to the SARNET framework that covers in a complete manner the historical aspects of water-cooled reactors safety principles and phenomena concerning in-vessel accident progression, early and late containment failure, fission product release, and transport in RCS and containment. It contains also a description of reference analysis tools or computer codes, of management and termination of a SA sequence, as well as of the environmental management. This unique reference book emphasizes the prevention and management of a SA, in order to teach nuclear professionals how to mitigate potential risks to the public and the external environment to the maximum extent possible.

Other "spreading of excellence" activities foreseen inside this WP2 are the organisation of periodic European Review Meetings on Severe Accident Research (ERMSAR Conferences) and the mobility programme (MOB), under which university students and young researchers can go to internship programmes. These particular activities will be illustrated in the following part of the present paper.

3.1. The SA Courses. The SARNET one-week educational courses are mainly courses that focus on disseminating the knowledge gained on SA phenomenology in the last two decades principally to Master and Ph.D. students, young engineers and researchers while the two-day information and training courses are mainly foreseen for industry managers and senior scientists. So, there is a clear indication and separation for the audience of the specific course, to better satisfy the different requests and needs from the participants.

During the previous SARNET FP6 project, three short courses (1 week) on the different aspects of SA research were organized, by different partners, with a mixed content (not only phenomenology but also SAM and SA codes):

(i) SA phenomenology, including some description of the SAM,

(ii) SA progression (analysis, data and uncertainties) to give the order of magnitude of physical phenomena occurring during a SA progression to researchers and engineers working in industry and regulatory organisations, 


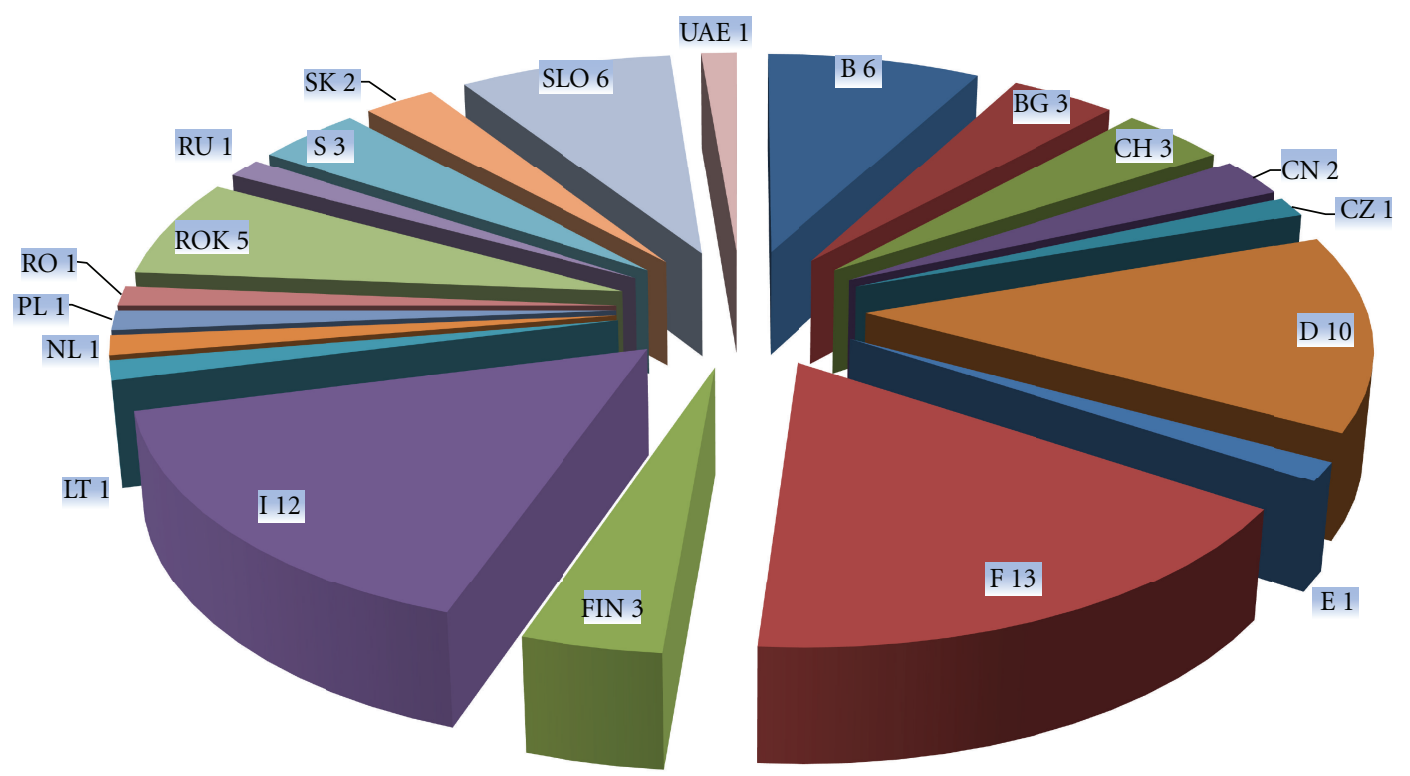

FIgURE 2: Nationalities of the participants in the Pisa 2011 course.

(iii) nuclear reactor SA analysis: application and management guidelines, focused more on SA methodology (models, codes), analyses, and SAM.

The first educational SARNET2 "Severe Accident Phenomenology Short Course" was organized in January 2011 by CEA and Pisa University and was hosted by the Engineering Faculty of Pisa University (Italy). The participation was quite high, with about 100 students from 20 worldwide countries (Figure 2) and a practical balance of gender for the participants. This Pisa course was again a oneweek course for education on phenomenology because the goal was also to refresh participant memories after 5 years and SARNET new outcomes, with a program covering not only SA phenomenology and progression in current water-cooled Gen. II NPPs, but also the different design solutions in Gen. III ones. The purpose of this course [16] was to describe Gen. III designs addressing SA (i.e., the "in-vessel" melt retention concept or the "ex-vessel" core catcher concept). SA phenomenology has been described through its progression in the core and in the vessel lower head up to vessel failure, followed by the ex-vessel accident progression, with the loadings which can cause an early containment failure (i.e., direct containment heating, hydrogen combustion in containment, steam explosion), or the late containment failure (i.e., MCCI, corium coolability, etc.) The source term with fission products release from the core and transport in the RCS and containment has been specially emphasized. Lecturers were experts from 8 different countries, with large skills and knowledge on Gen. III NPPs and on the progression of a SA. The presence of lecturers from nuclear industry was utilized to describe how the different NPPs would react during a SA, keeping in mind that an introductory course would not allow lengthy discussions or computer simulations. The Pisa course was open to university students with a very strong discount fee and contributed for 3 ECTS (with a mandatory written work) as an advanced course for Master students, with a strong link among SARNET, ENEN, and European Master of Science in Nuclear Engineering (EMSNE).

An evaluation form was distributed during the last days of the course to the participants to analyse the course and its impact. The evaluation was generally made on a scale from 1 (very bad) to 5 (very good). The evaluation of the general organisation of the course was very good for the overall mark: 4.32/5. Participants have not expressed a main field of interest for reactor applications, with a quite equilibrated distribution of this interest between Gen. II and Gen. III reactor design and the lectures had an average mark of 3.86/5, with no BAD or VERY BAD marks. Finally, it can be stated that the course met very well the participant expectations in terms of personal objectives in the field of SA as can be highlighted from the distribution of answers at the main question "You have participated to the course in order to reach your own objectives in the field of SA, after the course, do you estimate that these objectives have been reached?": the MAINLY answer had 70.5\% while the TOTALLY $17.9 \%$, without NOT AT ALL mark. The suggestions reported in the forms also provide an indication for the planning of the future courses, again on SA phenomenology, reducing the focus on codes (more models, less codes). 


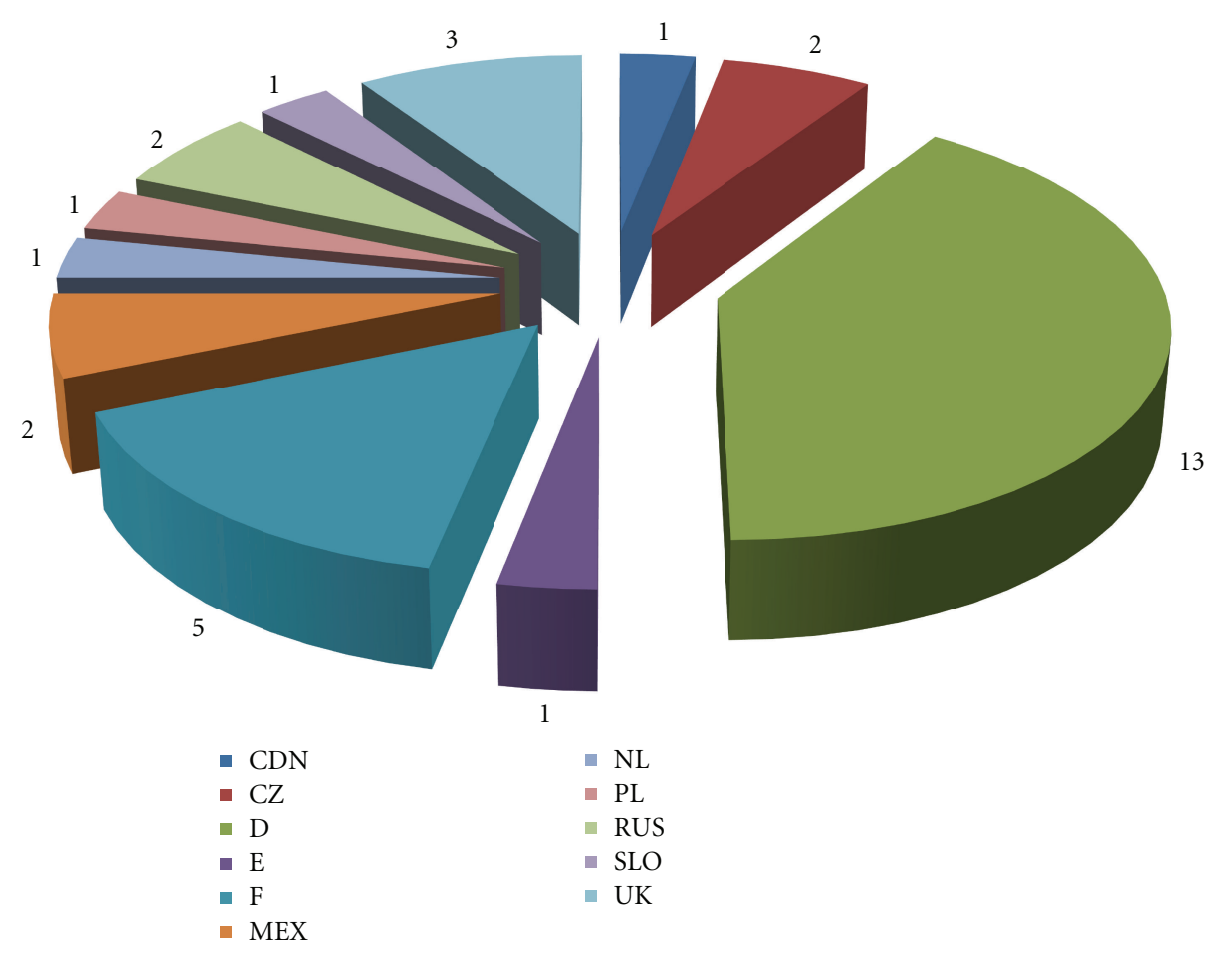

FIGURE 3: Nationalities of the participants in the KIT 2012 course.

The second SARNET two-day course was an information and training one. It was entitled "Severe Accident Phenomenology and Management" and was hosted and organized in Karlsruhe (Germany) by KIT, in cooperation with various SARNET partners, in July 2012. The goal of this last course was quite different respect to the previous one because it was mainly focused on disseminating the knowledge gained on severe accidents in the last two decades primarily to managers and senior scientists. The KIT course program covered SA phenomenology and progression in current water-cooled Gen. II and III NPPs with the following main topics:

(i) historical overview including a review of TMI, Chernobyl, and-above all-Fukushima accidents,

(ii) short introduction to the SA phenomenology,

(iii) overview of the main SA codes (in priority ASTEC and MELCOR),

(iv) severe Accident Management Guidelines,

(v) backfitting of Gen. II NPP and SA mitigation for Gen III plants,

(vi) radiological consequences to the environment and to the public resulting from a SA.

Lectures have been given by 10 international experts from major nuclear institutes, industries, and universities working on the SA topic. As expected, the participation at this course was good but lower respect to the Pisa course, considering the particular high level target of the audience, with 32 participants but from 11 worldwide countries (see Figure 3 for the distribution).

The next SARNET course will be again an educational one-week course, based on the skeleton of the Pisa one, following the strong requests to repeat this kind of phenomenological course received from different worldwide organisations after the Fukushima accident.

3.2. The Mobility Programme. The Mobility Programme (MOB) aims at training young researchers and students through a delegation towards SARNET research teams, in order to enhance the exchanges and the dissemination of knowledge on SA area. In this $\mathrm{MOB}$ programme, the long-term goal is to build and strengthen teams which would engage together in a certain activity of the excellence network. A total of 33 mobility actions (with an average duration of 3 months) were completed at the end of the SARNET FP6 project, where most of the delegates were from Eastern Europe countries (as defined in the EU EuroVoc multilingual thesaurus) going to laboratories and universities in Western Europe countries and a large fraction of the delegates were women. The dominant area of training was on the use of the ASTEC code.

In SARNET2 FP7 an increased financial support covering partially the delegation costs (maximum of $2000 € /$ month) is provided. To apply for mobility support, the following conditions shall be fulfilled: organisations shall be SARNET members (or only the hosting one for the delegation of an university master/Ph.D. students), the work to be 


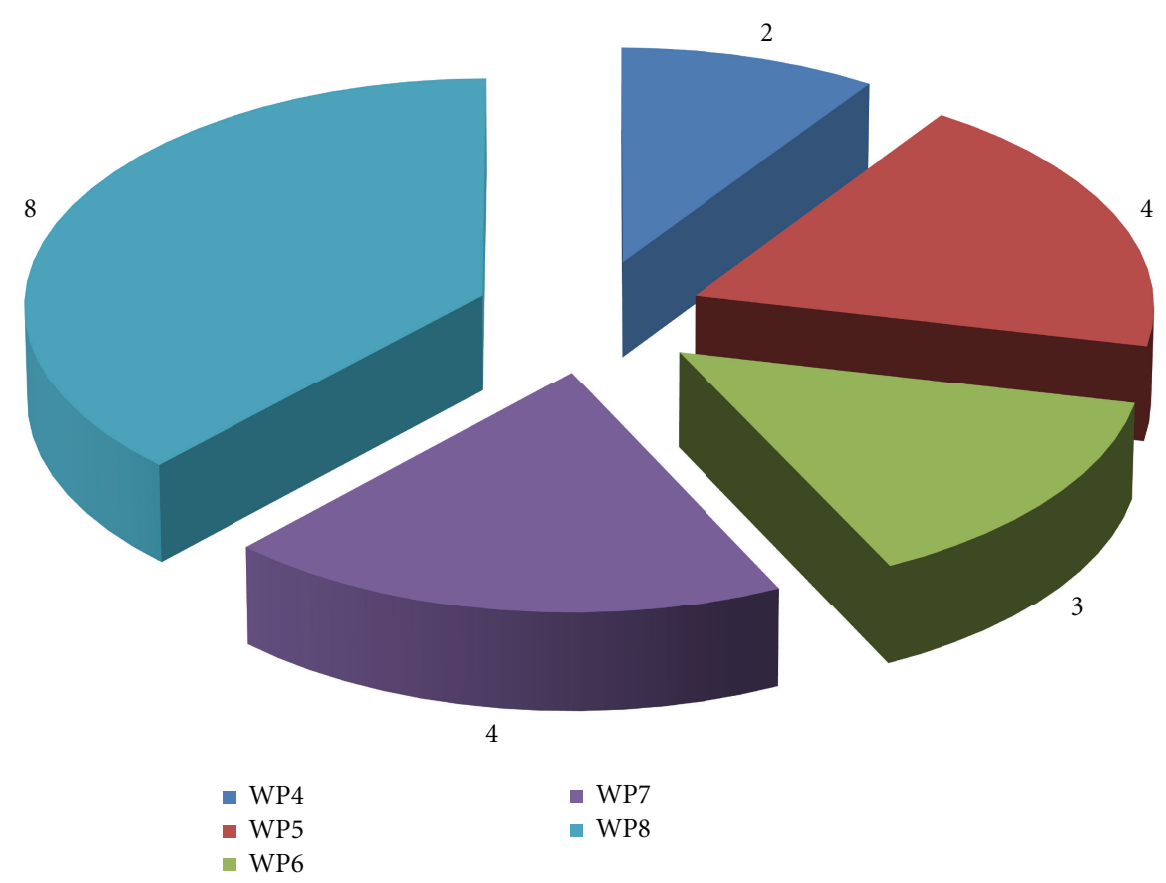

Figure 4: Distribution of the SARNET2 MOB actions.

performed during the delegation period shall be relevant to SARNET objectives and be part of the JPA, the delegation shall contribute to the transfer of knowledge/know-how. The allocation of funds is subject to the final delivery of an open delegation report describing the main technical achievements. The number of these mobility actions is one of the several integration indicators defined in order to assess the progress of the SARNET2 FP7 project and the success of the network integration: in total 21 mobility actions have been authorized, with the distribution among the different WPs reported in Figure 4, without the request for a dominant topic as in SARNET FP6 (although a predominance of WP8 is present), a good balance of gender (Figure 5), and an average time duration of about 4 months.

For the success of this SARNET MOB programme, strong partners' efforts were needed to highlight research projects which could be of interest to young researchers or students and to disseminate internally and externally the understanding of the benefits of this MOB program. In this context an attractive idea has been to arrange, for the university delegates, to perform a master thesis and/or to take courses in SA technology in the EMSNE framework, funding the master thesis stages in the SA field to be performed to obtain the 20 ECTS necessary for the EMSNE achievement.

3.3. ERMSAR Conferences. Five ERMSAR (European Review Meetings on Severe Accident Research) conferences have been organized successively in France, Germany (twice), Bulgaria, and Italy as an exchange forum for the whole international SA community. The proceedings of these ERMSAR Conferences are available for download on the SARNET2 public website.

The 4th ERMSAR conference was hosted by ENEA in Bologna (Italy) on May 11-12, 2010. It gathered 98 participants from 24 different nationalities (8 non-EC countries and 15 EC ones). The SARNET partners presented papers on their joint work, including some first conclusions of the work done in the first period.

The latest 5th ERMSAR conference was the first one fully open to the international community. It has been hosted by GRS in Cologne (Germany) on 21-23 March 2012, gathering 157 participants with 52 presented papers, not only by SARNET partners. The participants came from 60 organisations and 27 countries (42 of them were coming from non-SARNET partners). This seminar aimed at presenting the current status of R\&D on SAs both in Europe and elsewhere, as an "open conference." Therefore, beside the presentations of the current work by SARNET members in the network JPAs, non-SARNET organisations were invited to contribute through papers and presentations to the seminar or the SARNET members were also able to present SA individual work conducted outside the JPAs. The four previous ERMSAR conferences provided insights on the SARNET network activities and in particular on the SA research priorities established in 2008. On the contrary, the global objective of this 5 th seminar has been to present the recent progress of international knowledge on SAs, of course including the work done within the SARNET network in the last two years. It was also an opportunity to discuss future 


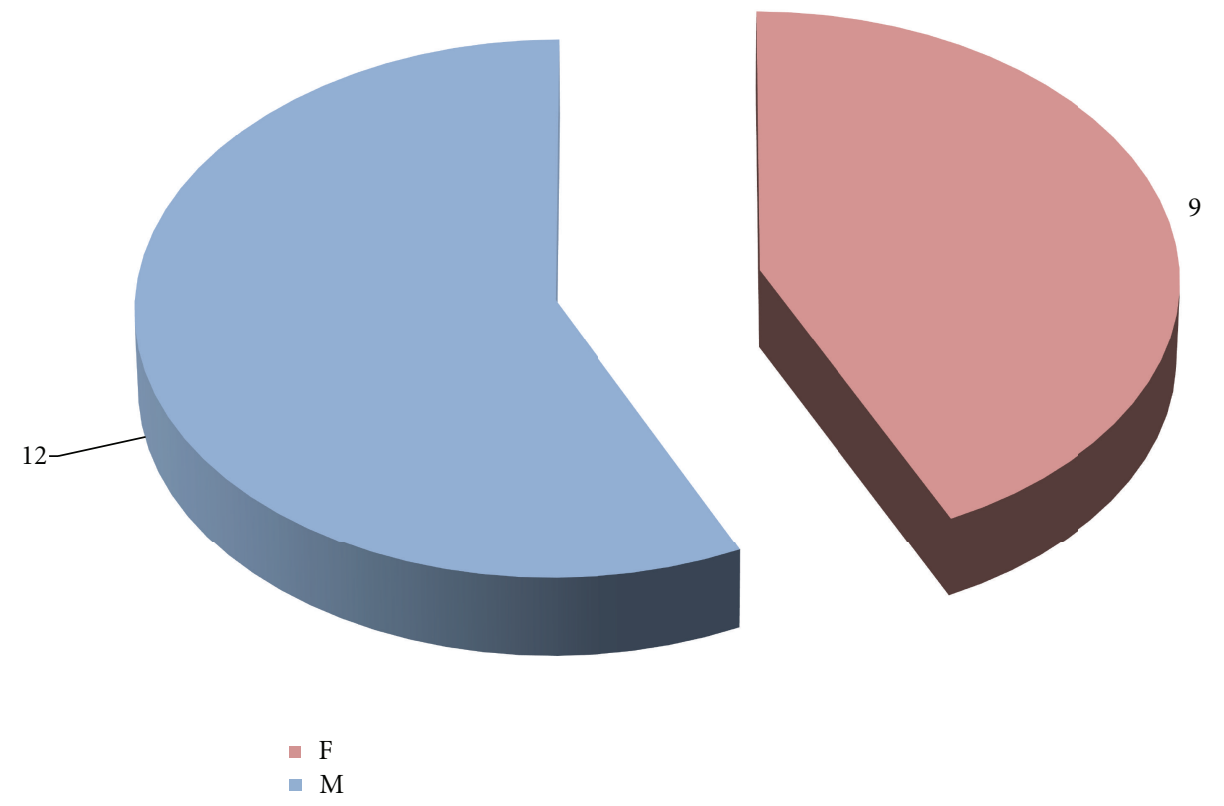

FIgURE 5: Distribution of gender for MOB actions.

$\mathrm{R} \& \mathrm{D}$ priorities on SAs and, in particular, how the feedback of the Fukushima accident can be taken into account in planning the new research needs.

The final ERMSAR 6th Conference will present all the results of the whole SARNET project.

\section{Conclusions}

After a first phase of four and a half years, the SARNET network of excellence continues from April 2009 for four years more on the different SA research lines. SARNET aims both at solving the latest "open" issues in this field for current NPPs safety and at consolidating the sustainable integration of the European SA research capacities. Efforts have also continued on the preservation and the transfer of knowledge to younger generations through the different "spreading of excellence" activities, including the publication of the SA text book, the organisation of the education and training courses, and other different actions.

The work done on the ASTEC code assessment and improvements will reinforce ASTEC position of European reference SA code. It will allow preservation of knowledge produced by thousands of person-years of $\mathrm{R} \& \mathrm{D}$ and dissemination to end-users.

Links with OECD/NEA and other programmes cofunded by the EC will be maintained and reinforced, in particular with ENEN association for education and training courses for students and young researchers, and with NUGENIA (a non-profit-making association dedicated to the research and development of nuclear fission technologies, with a focus on Gen. II and III NPPs, gathering stakeholders from industry, research, safety organisations, and academia and committed to develop joint R\&D projects in this field) and SNETP (the European stakeholder forum for nuclear technology). Finally, in order to keep the competence in SA and SAM alive after the SARNET2's end in 2013, a self-sustaining entity in the field of SA research is under construction in close links with NUGENIA.

\section{Acknowledgment}

The authors thank the European Commission for funding the SARNET network in FP7 (Project SARNET2 no. 231747 in the area "Nuclear Fission and Radiation Protection").

\section{References}

[1] D. Magallon, A. Mailliat, J. M. Seiler et al., "European expert network for the reduction of uncertainties in severe accident safety issues (EURSAFE)," Nuclear Engineering and Design, vol. 235, no. 2-4, pp. 309-346, 2005.

[2] B. Schwinges, "Ranking of SA Research Priorities in the Frame of SARNET," in Proceedings of the European Review Meeting on Severe Accident Research (ERMSAR '08), Nesseber, Bulgaria, 2008.

[3] J. C. Micaelli, J. P. Van Dorsselaere, B. Chaumont et al., "SARNET: a European Cooperative effort on LWR severe accident research," in Proceedings of the European Nuclear Conference, Versailles, France, 2005.

[4] J. P. Van Dorsselaere, C. Seropian, P. Chatelard et al., "The ASTEC integral code for severe accident simulation," Nuclear Technology, vol. 165, no. 3, pp. 293-307, 2009.

[5] J. P. Van Dorsselaere, A. Auvinen, D. Beraha et al., "The European Research on Severe Accidents in Generation-II and -III Nuclear Power Plants," Science and Technology of Nuclear Installations, vol. 2012, Article ID 686945, 12 pages, 2012. 
[6] B. Clément and R. Zeyen, "The Phébus FP and international source term programmes," in Proceedings of the International Conference on Nuclear Energy for New Europe, Bled, Slovenia, 2005.

[7] R. Zeyen, "European approach for a perennial storage of Severe Accident Research experimental data, as resulting from EU projects like SARNET, Phébus FP and ISTP," in Proceedings of the ANS Winter Meeting, Washington, DC, USA, 2009.

[8] K. Mueller, S. Dickinson, C. de Pascale et al., "Validation of severe accident codes on the phebus fission product tests in the framework of the PHEBEN-2 project," Nuclear Technology, vol. 163, no. 2, pp. 209-227, 2008.

[9] B. Clément, T. Haste, E. Krausmann et al., "Thematic network for a Phebus FPT1 international standard problem (THENPHEBISP)," Nuclear Engineering and Design, vol. 235, no. 2-4, pp. 347-357, 2005.

[10] M. T. Farmer, "A summary of findings from Melt Coolability and Concrete Interaction (MCCI) Program," in Proceedings of the International Congress on Advances in Nuclear Power Plants (ICAPP '07), Nice, France, 2007.

[11] C. Journeau, J. F. Haquet, P. Piluso, and J. M. Bonnet, "Differences between silica and limestone concretes that may affect their interaction with corium," in Proceedings of the International Conference on Advances in Nuclear Power Plants (ICAPP '08), pp. 1233-1240, Anaheim, Calif, USA, June 2008.

[12] J. Malet, L. Blumenfeld, S. Arndt et al., "Sprays in containment: final results of the SARNET spray benchmark," Nuclear Engineering and Design, vol. 241, no. 6, pp. 2162-2171, 2011.

[13] W. Ambrosini, M. Bucci, N. Forgione, F. Oriolo, and S. Paci, "Quick look report on SARNET2 condensation benchmark-2 results," Report DIMNP RL 1252, University of Pisa, Pisa, Italy, 2010.

[14] S. Kelm, P. Broxtermann, S. Krajewski, and H. J. Allelein, Report on the Generic Containment Code-To-Code ComparisonRun0, Forschungszentrum, Jülich, Germany, 2010.

[15] B. Sehgal, Ed., Nuclear Safety in Light Water Reactors-Severe Accident Phenomenology, Academic Press, 2012.

[16] S. Paci and P. Piluso, SARNET2 Short Course on Severe Accident Phenomenology, Dedizioni, Pisa, Italy, 2012. 

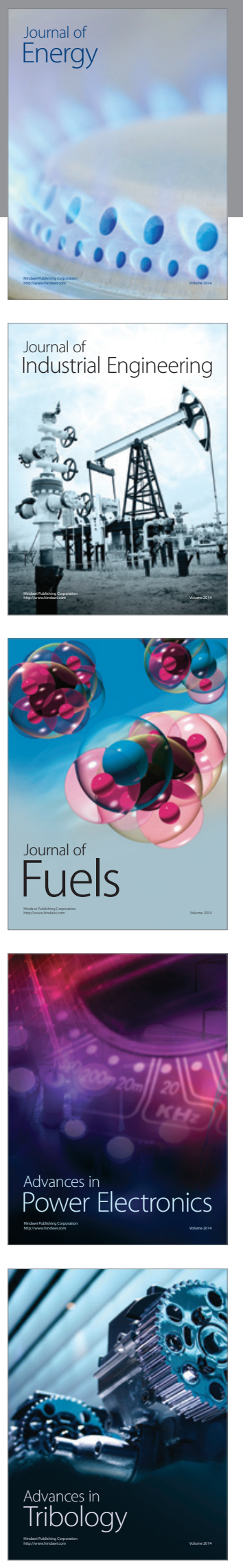
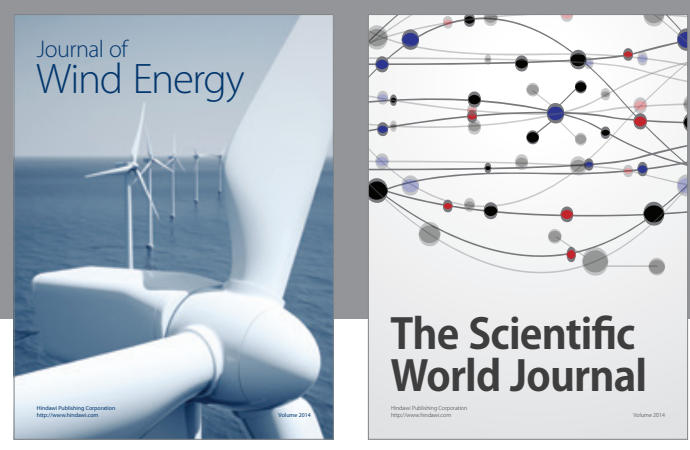

The Scientific World Journal

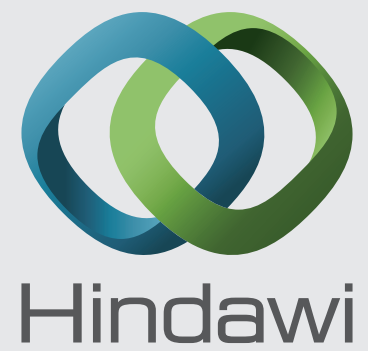

Submit your manuscripts at http://www.hindawi.com
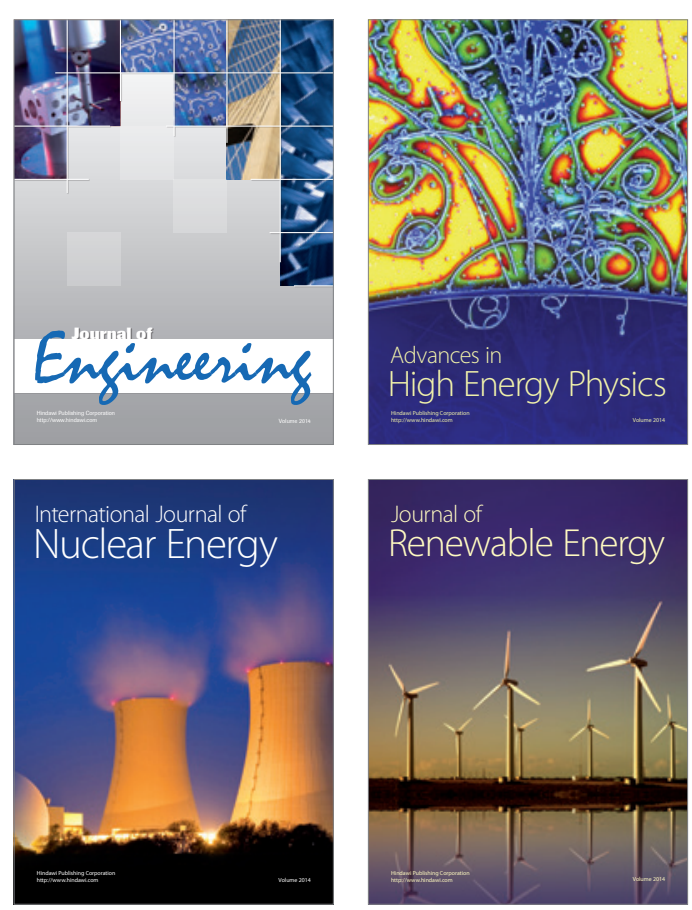

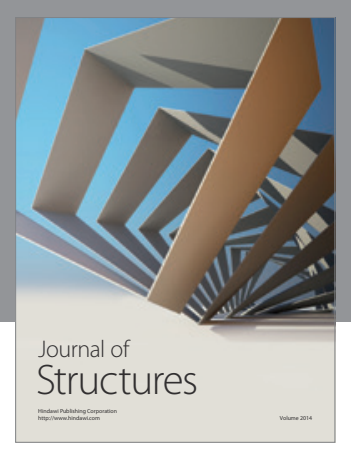

Rotating
Mechinery
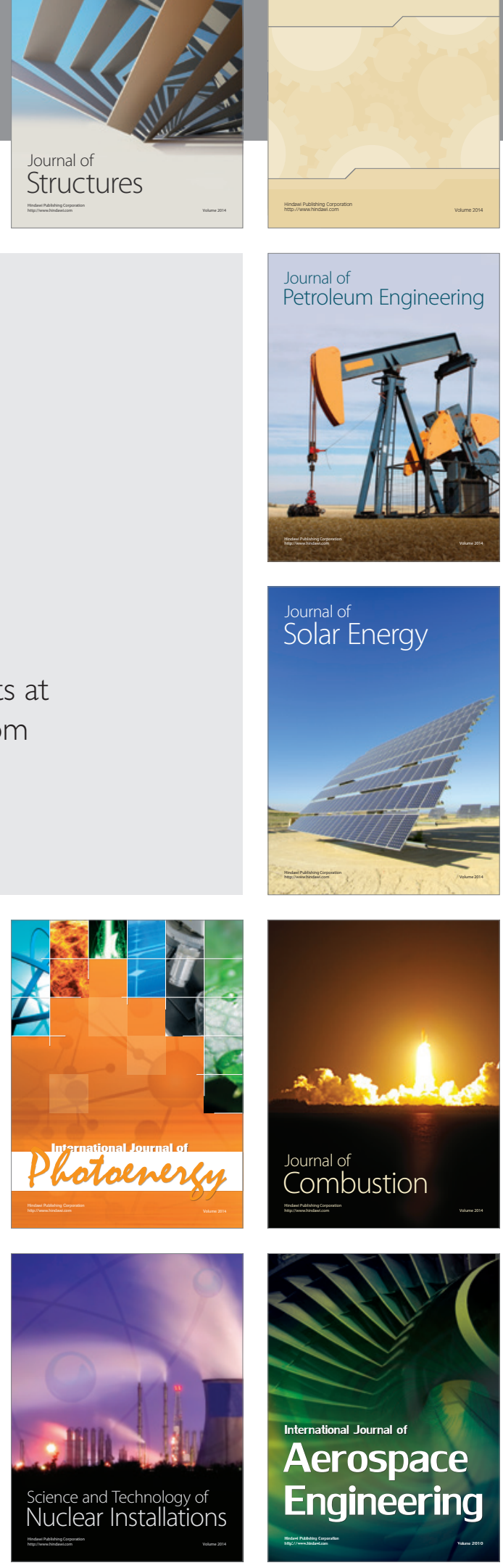